
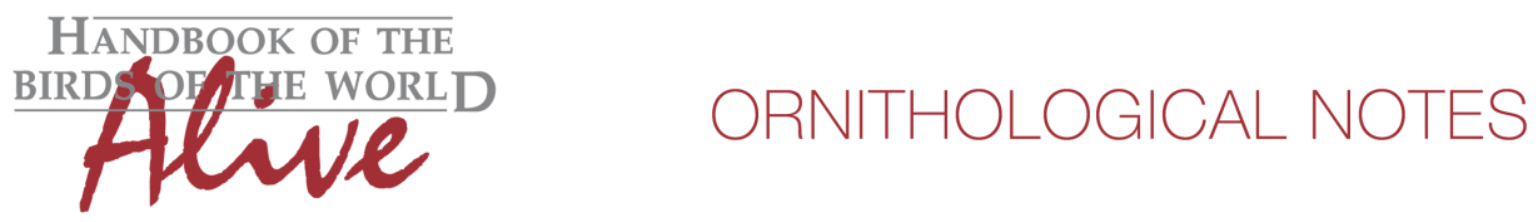

\title{
Notes on the vocalizations of Yellow-breasted Apalis (Apalis flavida)
}

Peter Boesman

In the following we briefly analyze and compare voice of the different races of Yellowbreasted Apalis (Apalis flavida). We also try to quantify the extent of any vocal differences using the criteria proposed by Tobias et al. (2010), as a support for taxonomic review. We have made use of sound recordings available on-line from Xeno Canto (XC).

Our main interest is to compare song of the morphologically distinct races flavocincta and viridiceps with others. Song in all races is structurally similar: a series of repeated identical complex notes. An overview with sonograms:
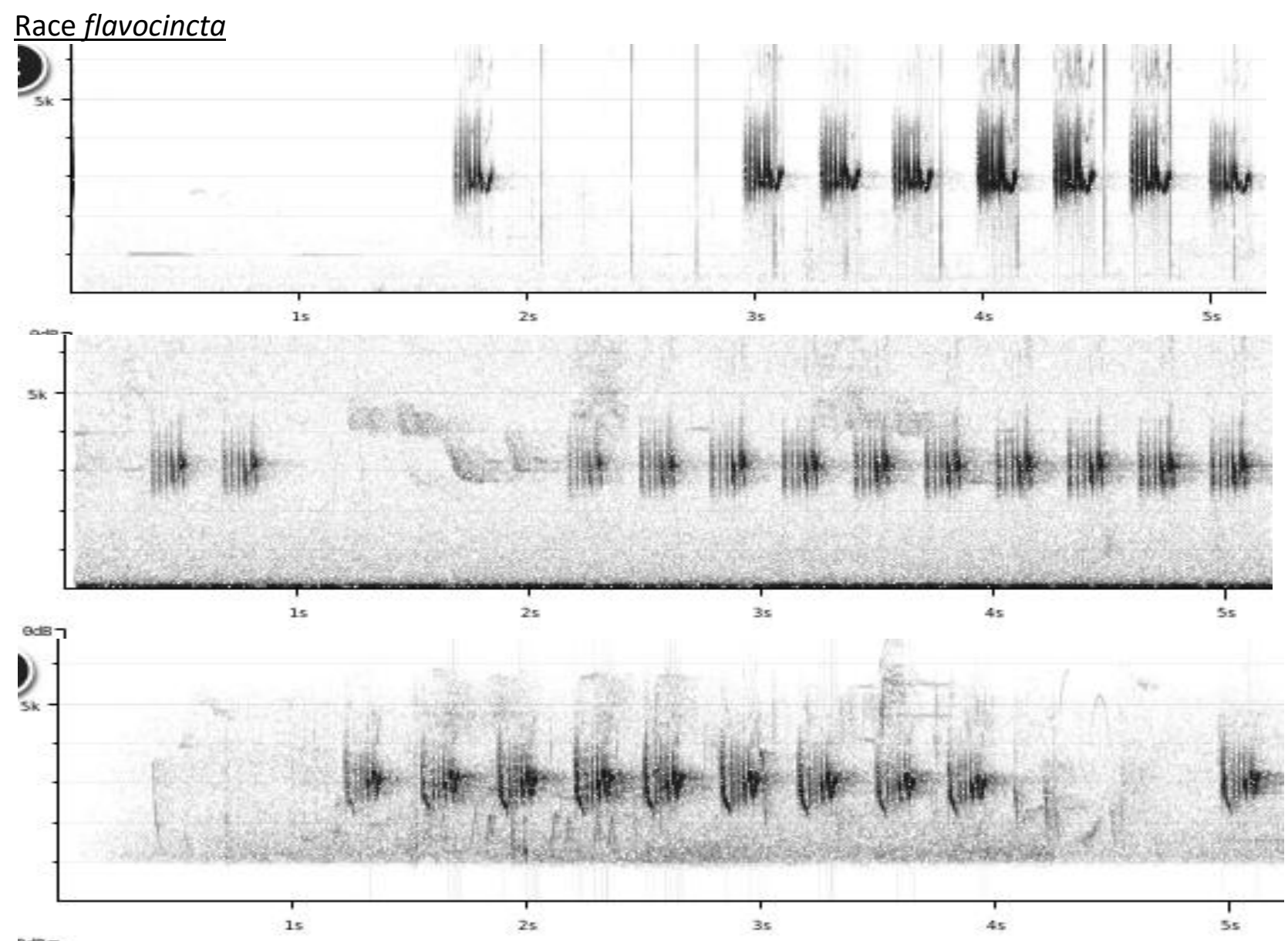

The repeated note seems to be consistently a short rattle ending with an emphasized note, with an overall rather rasping quality. 


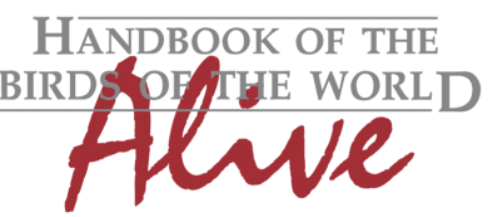

\section{ORNITHOLOGICAL NOTES}

\section{$\underline{\text { Race viridiceps }}$}
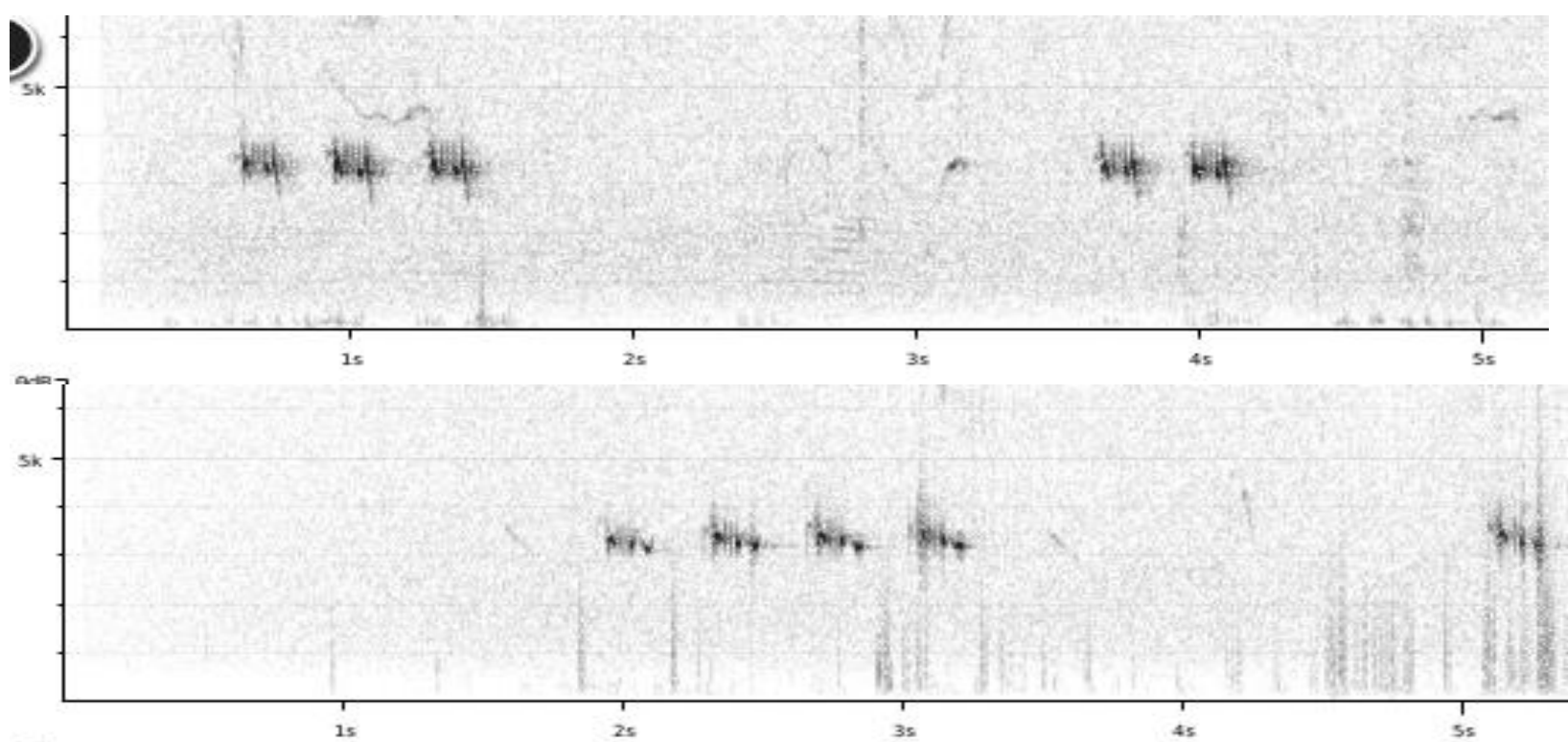

The repeated note seems to be a short rattle, but less rasping, slightly higher-pitched and mellower than flavocincta.

\section{Race pugnax}
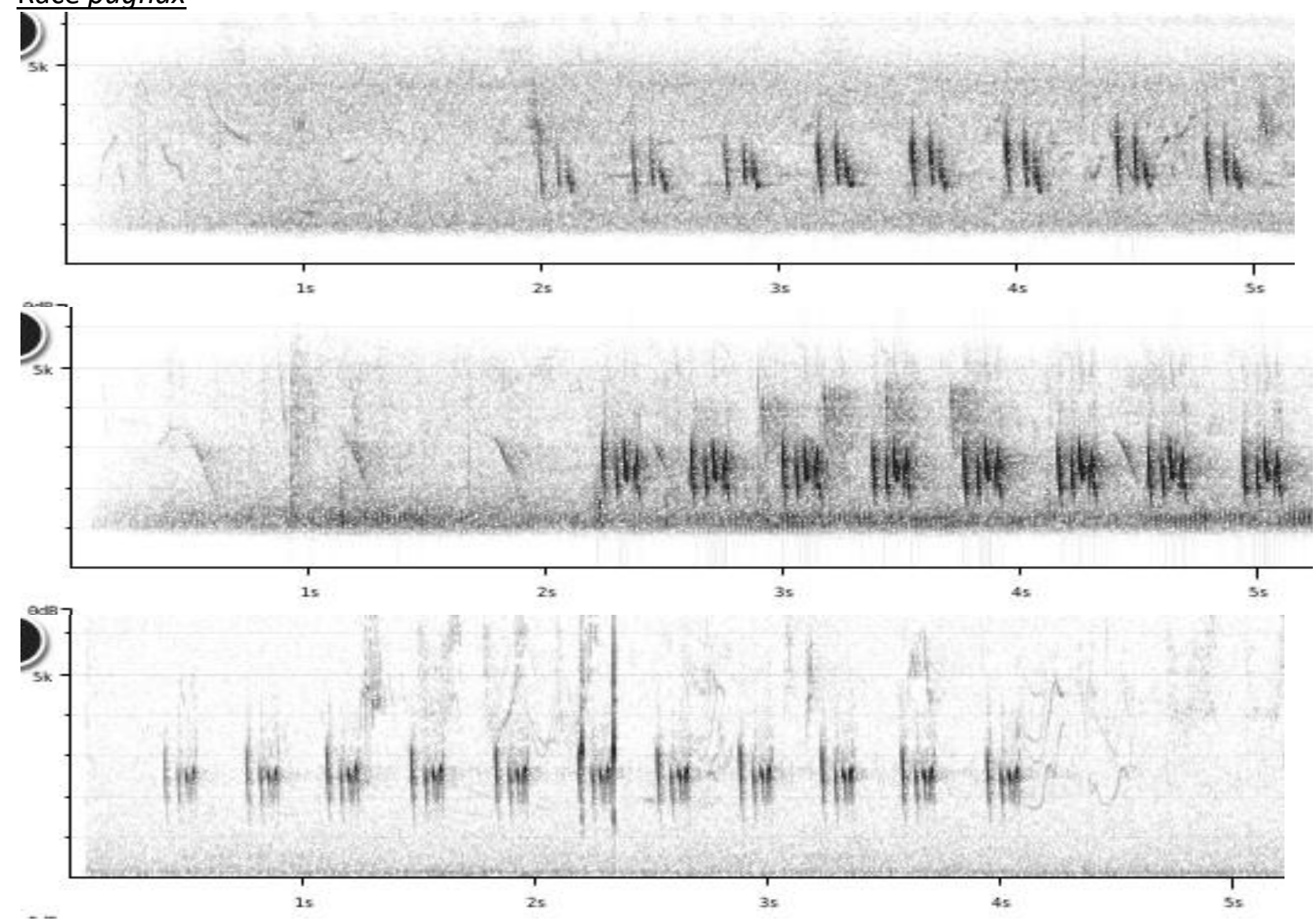

The repeated note sounds more bisyllabic "chirup..chirup..", apparently due to less note elements which are more spaced. Also clearly lower-pitched than previous races, with most note elements reaching frequencis lower than $2 \mathrm{kHz}$. 


\section{HANDBOOK OF THE \\ BIRDSPFGTE WORLD}

\section{ORNITHOLOGICAL NOTES}

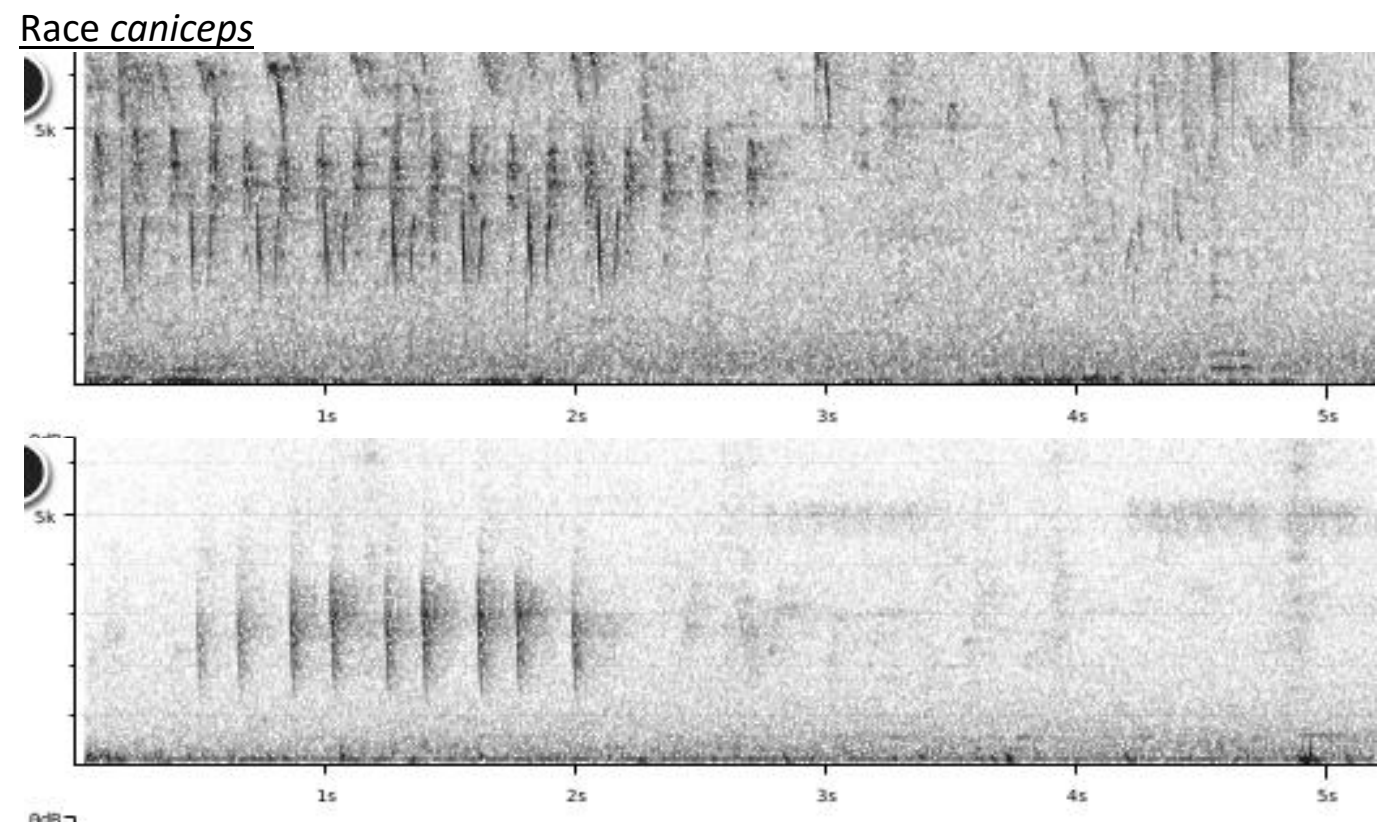

The repeated note apparently has even less elements here.

\section{Races flavida/florisuga/neglecta}

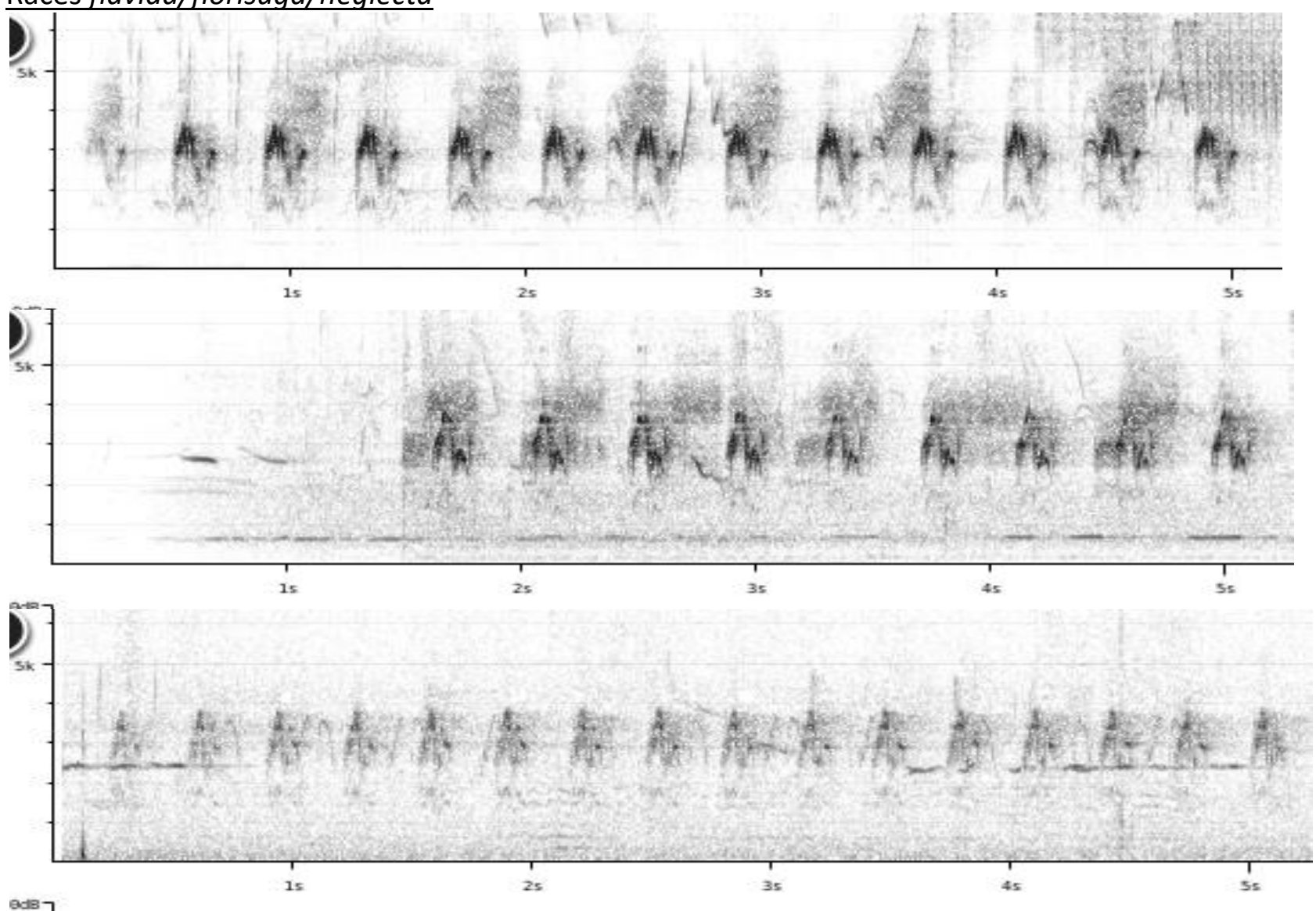

The repeated note is again different, sounding much more scratchy, and is nolonger a composition of distinct separate elements. There is also a clear frequency peak in the middle. 

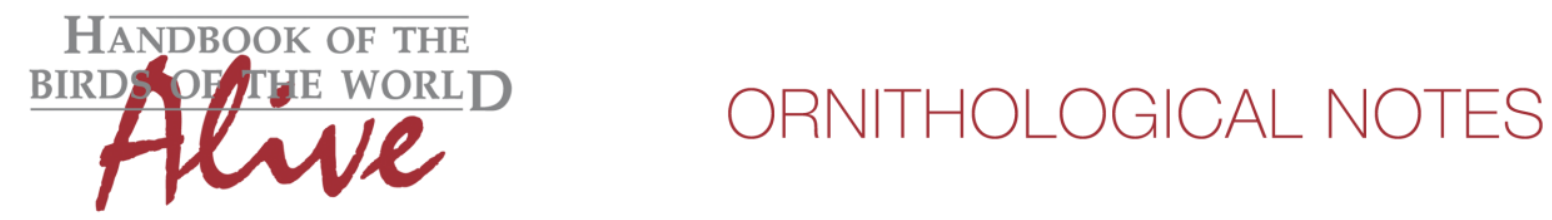

It would thus seem that there are three vocally distinct groups:

- the NE group (flavocincta/viridiceps)

- the west and central group (caniceps/pugnax)(no recordings of abyssinica)

- the southern group (flavida/florisuga/neglecta)

Each group differs vocally clearly from the other groups, and could be easily identified in a blind test (and at least in the two northern groups, it would seem that every race can be identified on its own).

We could score vocal differences of the three groups based on the following quantifiable parameters:

- The NE group has a repeated note which consists of 5 or more separated elements (interelement spaces smaller than element duration, sometimes almost linked, thus elements delivered at a fast rattling pace). All frequencies above $2.2 \mathrm{kHz}$. Max. freq. $4 \mathrm{kHz}$ or higher. - The west and central group has a repeated note which consists of 1-4 well-separated elements (inter-element spacing often larger than note length, especially between first two elements). Min. frequencies reach c. $1.8 \mathrm{kHz}$

- The southern group lacks distinct elements and notes have an irregular overslurred shape with apparently a very weak fundamental frequency below $2 \mathrm{kHz}$.

NE group thus differs mainly because of a rattled series of elements (2) which are slightly higher-pitched (1).

This note was finalized on 9th February 2016, using sound recordings available on-line at that moment. We would like to thank in particular the sound recordists who placed their recordings for this species on XC: Jason Anderson, Peter Boesman, James Bradley, Marcell Claassen, Tim Cockroft, Rolf de By, Charles Hesse, Rory Nefdt, Stein Nilson, Bram Piot, Derek Solomon, Andrew Spencer and Martin St-Michel.

\section{References}

Tobias, J.A., Seddon, N., Spottiswoode, C.N., Pilgrim, J.D., Fishpool, L.D.C. \& Collar, N.J. (2010). Quantitative criteria for species delimitation. Ibis 152(4): 724-746.

\section{Recommended citation}

Boesman, P. (2016). Notes on the vocalizations of Yellow-breasted Apalis (Apalis flavida). HBW Alive Ornithological Note 222. In: Handbook of the Birds of the World Alive. Lynx Edicions, Barcelona. (retrieved from http://www.hbw.com/node/932181 on 7 September 2016). 